\title{
Small Lymphocytic Lymphoma: Analysis of Two Cohorts Including Patients in Clinical Trials of the German Chronic Lymphocytic Leukemia Study Group (GCLLSG) or in "Real-Life" Outside of Clinical Trials
}

\author{
SOTIRIOS SACHANAS ${ }^{1}$, GERASSIMOS A. PANGALIS ${ }^{1}$, ANNA-MARIA FINK ${ }^{2}$, \\ JASMIN BAHLO $^{2}$, KIRSTEN FISCHER $^{2}$, GEORGIA LEVIDOU ${ }^{3,4}$, MARIE-CHRISTINE KYRTSONIS ${ }^{5}$, \\ VASSILIKI BARTZI ${ }^{6}$, THEODOROS P. VASSILAKOPOULOS ${ }^{7}$, CHRISTINA KALPADAKIS ${ }^{8}$, \\ EFSTATHIOS KOULIERIS ${ }^{1}$, MARIA MOSCHOGIANNIS ${ }^{1}$, XANTHI YIAKOUMIS ${ }^{1}$, PANTELIS TSIRKINIDIS ${ }^{1}$, \\ MARIA K. ANGELOPOULOU ${ }^{7}$, BARBARA EICHHORST ${ }^{2}$ and MICHAEL HALLEK ${ }^{2}$ \\ ${ }^{1}$ Department of Haematology, Athens Medical Center-Psychikon Branch, Athens, Greece; \\ ${ }^{2}$ Department I of Internal Medicine \& Center of Integrated Oncology Cologne-Bonn, \\ German CLL Study Group, University Hospital Cologne, Cologne, Germany; \\ ${ }^{3}$ Pathology Department, University of Athens, Athens, Greece; \\ ${ }^{4}$ Pathology Department, Humanpathologie GmbH, Erlangen, Germany; \\ ${ }^{5} 1$ st Department of Propedeutics, University of Athens, Laikon General Hospital, Athens, Greece; \\ ${ }^{6}$ Department of Haematology, General Hospital of Karditsa, Karditsa, Greece; \\ ${ }^{7}$ Department of Haematology, University of Athens, Laikon General Hospital, Athens, Greece; \\ ${ }^{8}$ Department of Haematology, University Hospital, University of Crete, Heraklion, Greece
}

\begin{abstract}
Background: Only few studies have focused exclusively on patients with small lymphocytic lymphoma (SLL). Patients and Methods: In the present report, 103 SLL patients were analyzed from both, clinical trials of the German Chronic Lymphocytic Leukemia Study Group and Greek centers, and emphasis was placed on the therapeutic strategy. The impact of lymph node characteristics, such as the presence of proliferation centers (PCs) on response and survival was also assessed. Results: SLL patients included in clinical trials were treated mostly with fludarabine-based regimens while those in "reallife" were staged and treated mostly as patients with low-grade lymphomas. Our analysis showed a trend for better survival for patients with SLL without detectable PCs. Conclusion: Patients with SLL outside of clinical trials are usually treated as cases of lymphoma. In addition, this analysis supports published data regarding the adverse prognostic value of the presence of PCs in lymphoid nodes in SLL.
\end{abstract}

Correspondence to: Sotirios Sachanas, MD, Ph.D., Department of Haematology, Athens Medical Center-Psychikon Branch, 1 Andersen str. 11525, Athens, Greece. Tel: +30 2106974076, Fax: +30 2106984627, e-mail: ssachanas@gmail.com

Key Words: Small lymphocytic lymphoma, treatment, proliferation centers.
Small lymphocytic lymphoma (SLL) comprises approximately $7 \%$ of newly-diagnosed cases of non-Hodgkin's lymphomas (NHL) (1). At the time of diagnosis most patients presented with advanced-stage disease including generalized lymphadenopathy, hepatosplenomegaly and bone marrow involvement $(2,3)$.

According to the World Health Organization (WHO) classification of lymphoid tumors, B-cell chronic lymphocytic leukemia (B-CLL) and SLL without a fixed proportion of circulating B-lymphocytes are considered different forms of the same disease (4). In addition, according to the updated WHO classification there are patient subsets with lymph node involvement by SLL in whom lymphadenopathy was $<1.5 \mathrm{~cm}$, showing no proliferation centers (PCs). These cases are considered as the tissue counterpart of monoclonal B-lymphocytosis and have a good prognosis (5).

In contrast, the presence of large/confluent PCs with a high proliferative fraction has been shown to have an independent poor prognostic impact. However, these observations are only based on a single retrospective study and still need further confirmation (6).

Studies on SLL published until now have included heterogeneous groups of patients and did not use modern diagnostic criteria or included CLL patients per definition with more than 5000 lymphocytes/mL (7-8). 
Furthermore, outside the context of clinical trials, SLL patients are generally not treated uniformly and because of this there are little data available concerning the impact of different treatment options on response and survival.

In the present report we record clinical and biological features as well as treatment strategies in a series of SLL patients treated according to the study protocols. Results and clinical observations are compared to a patient cohort managed outside of controlled clinical trials focusing on the differences between these two patient cohorts. We also studied the impact of lymph node characteristics, such as the size and the presence of PCs, on response and survival of patients with SLL.

\section{Patients and Methods}

Patients diagnosed with SLL in three Greek centers from 2007 up to 2016 according to the 2008 WHO Classification diagnostic criteria, form the basis of this study, as well as SLL patients who had been included in six prospective clinical trials of the German Chronic Lymphocytic Leukemia Study Group (GCLLSG) (CLL1, CLL4, CLL5, CLL7, CLL8 and CLL2M) (4, 9-13).

Thus, two patients' cohorts were examined - one from Greece (retrospective analysis of chart review) and one from Germany (information on clinical trial patients) $(4,9-13)$.

Clinical and biological patients' characteristics were recorded as well as treatment related variables, such as, type of treatment administered, overall clinical response and outcome/survival. Apart from Binet clinical staging the Ann-Arbor staging system was also used in Greek cohort.

Moreover, lymph node (LN) features such as size, and histological evidence for the presence of lymph node PCs were recorded for Greek patients, whenever lymph node biopsies were performed and data were available. For histopathology, PCs were evaluated in hematoxylin and eosin sections and defined as pale areas containing prolymphocytes and paraimmunoblasts, surrounded by a dark background of small lymphocytes (14-17).

Involved LNs were defined as any LN greater than $1 \mathrm{~cm}$ detected by clinical or imaging assessment.

Statistical analysis. Data analyses were based on descriptive statistics. For continuous variables, these statistics included the following: median, minimum and maximum as well as interquartile range. The therapeutic regimen or agents given as first line treatment administered and treatment dates were documented, as well as treatment outcome, such as general response and time to relapse. Hence, time to first line treatment (TTFT, from diagnosis until starting first-line treatment), progression-free survival (PFS, from the start of first line treatment until the date of disease progression or death) and overall survival (OS, from diagnosis until death) were calculated according to Kaplan-Meier methodology. The effect of various clinicopathologic and laboratory parameters on clinical outcome was assessed by plotting survival curves according to the Kaplan-Meier method and comparing groups using Cox proportional hazards estimation. Statistical calculations were performed using the statistical package STATA 11.0 for Windows (Stata Corp. College Station, TX, USA) and SPSS Version 24 (SPSS Inc, Chicago, IL, USA) for the Greek and German analysis
Table I. German Chronic Lymphocytic Leukemia Study Group (GCLLSG) cohort.

\begin{tabular}{lc}
\hline Population analysis & Total N (\%) \\
\hline All patients (trial cohort), N & 53 \\
CLL1 & $6(11.3)$ \\
CLL4 & $1(1.9)$ \\
CLL5 & $2(3.8)$ \\
CLL7 & $8(15.1)$ \\
CLL8 & $33(62.3)$ \\
CLL2M & $3(11.3)$ \\
\hline
\end{tabular}

respectively. All results with a two-sided $p \leq 0.05$ were considered statistically significant.

\section{Results}

A total of 103 patients with SLL were analyzed; 50 patients diagnosed and treated in three Greek centers outside of clinical trials and 53 patients included in six German clinical trials (Table I).The median age of patients in the Greek cohort was 69 years (range $=36-89$ years), and in the German cohort 61 years (range=35-79). Tissue material for the detection of PCs was available at diagnosis in $35(35 / 50$, $70 \%$ ) patients from the Greek cohort and among them 23 $(23 / 35,66 \%)$ presented with apparent PCs (Figure 1).

\section{Follow up and survival analysis (OS, PFS)}

Greek cohort. Thirty-nine patients $(39 / 50,78 \%)$ were alive after a median observation time of 40 months (0.7-117.3). 5year OS was $90.1 \%$ and 5-year PFS was 36\% (Figure 2).

Univariate analysis revealed that specific clinical parameters such as age ( $>65 \mathrm{y})(\mathrm{HR}=9.013, p=0.048)$, ECOG performance status $(\mathrm{HR}=4.225, p=0.021)$ and presence of $\mathrm{B}$ symptoms $(\mathrm{HR}=10.723, p=0.040)$ were associated with a worse OS. Although according to Kaplan Meier survival curves (Figure 3) a trend for a better OS in patients with no detectable PCs was observed, since all events occurred in the group of patients with detectable PCs, it failed to attain statistical significance in our analysis $(p=0.1823)$.

GCLLSG clinical trial cohort. Thirty-nine patients $(39 / 53,74 \%)$ were alive after median observation from diagnosis of 72.7 months (range $=16.5-149.0$ ); 5 -year OS was $86.2 \%$ and 5-y PFS from first-line treatment was $39.5 \%$ (Figure 2). Univariate analysis showed that the presence of $17 \mathrm{p}$-del was of statistical significance with regards to PFS (HR=10.156, $p=0.045$ ).

\section{Patient characteristics at first line treatment}

Twenty-seven $(27 / 50,54 \%)$ and $45(45 / 53,85 \%)$ patients from Greek and German cohorts respectively received first line treatment. The characteristics of the patients who received first line treatment at this time point are shown in Table II. 


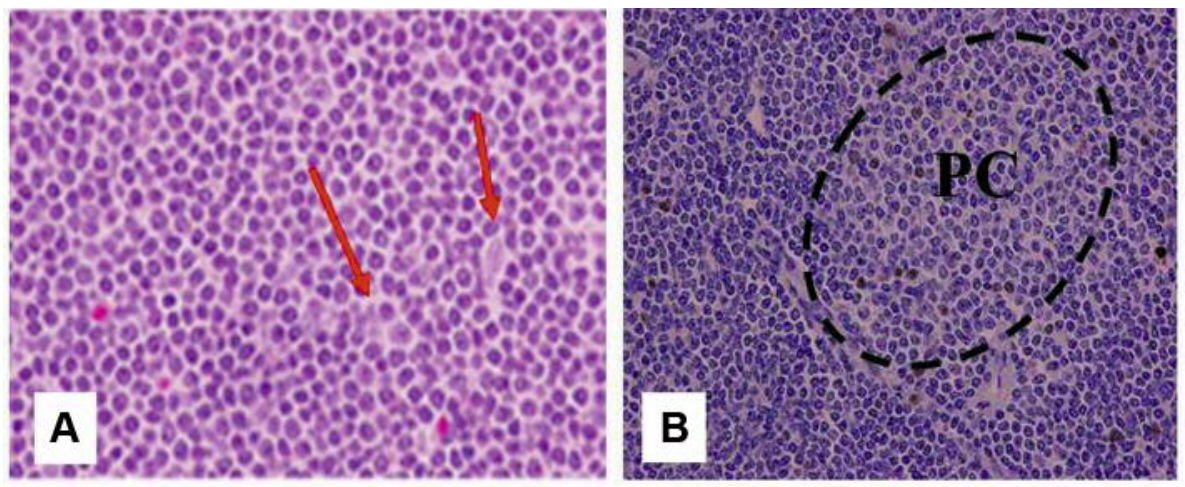

Figure 1. Representative immunostaining sections of a lymph node in a small lymphocytic lymphoma (SLL) patient demonstrating conventional morphology as well as the presence of proliferation center $(P C)$. A. Hematoxyline-Eosin $(\times 200)$ staining showing the presence of SLL infiltration combined with apparent prolymphocytes-paraimmunoblasts (red arrows). B. Ki67 immunostaining within and outside PC (Envision $\times 200)$. Stronger Ki67 staining within PC indicates the presence of paraimmunoblasts.
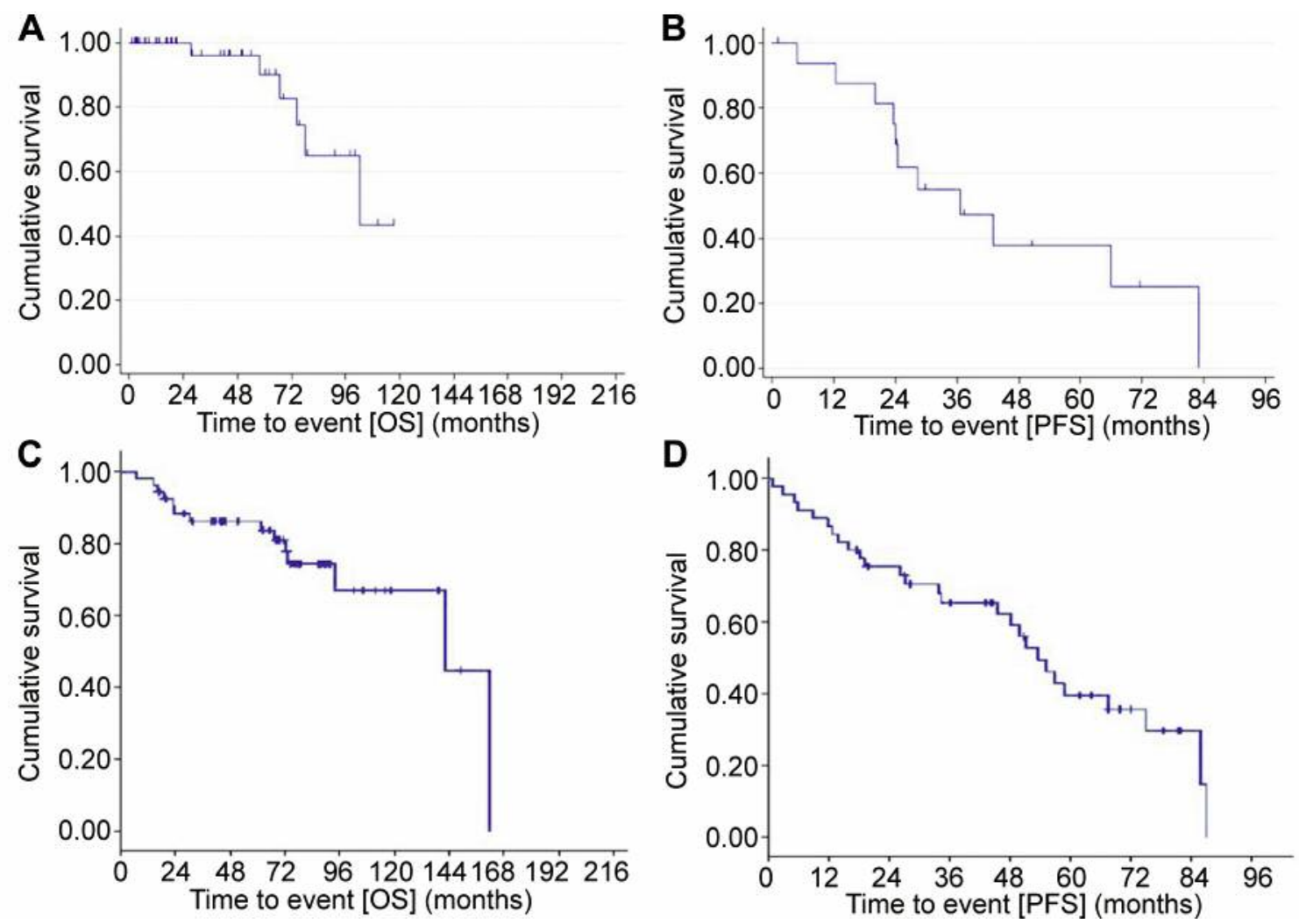

Figure 2. Overall survival (OS) and progression-free survival (PFS) - Greek cohort $(A, B)$ and German cohort $(C, D)$, respectively.

Greek cohort [27 patients (pts)]. Patients' median age was 70 years (range $=36-87$ ), while 18 of the 27 patients $(66 \%)$ were above the age of 65 years. Twenty-five patients $(92.5 \%)$ underwent bone marrow (BM) biopsy, showing a median SLL infiltration of $45 \%$ (range $=0-97 \%$ ). Ten patients $(37 \%$ ) presented with at least three involved LNs while 21 presented with $\mathrm{LN}>1.5$ $\mathrm{cm}$ as measured in computed tomography (CT). Detection of
$17 \mathrm{p}$ del, 11q del and IGHV mutation analysis were performed in only 11,8 and 8 cases respectively. One patient presented with $17 \mathrm{pdel}$, one with 11q del and five were unmutated.

GCLLSG clinical trial cohort (43 patients). Patients' median age was 62 years (range $=40-80)$ and $14(31.1 \%)$ were $>65$ years old. Nine underwent bone marrow biopsy and the 


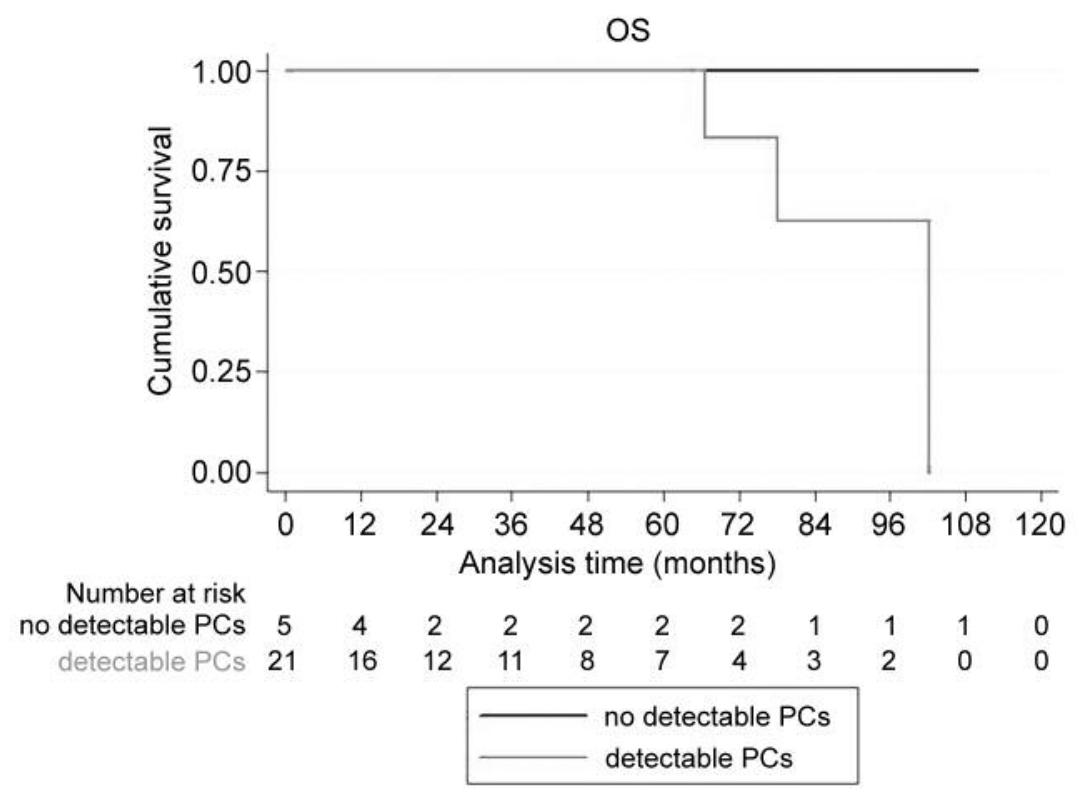

Figure 3. Overall survival (OS) of small lymphocytic lymphoma (SLL) patients according to the presence of proliferation centers (PCs) - Greek cohort.

median bone marrow infiltration was $60 \% ; 25$ of 45 patients (55.6\%) presented with $\mathrm{LN}>1.5 \mathrm{~cm}$ as measured on CT and $30(66.7 \%)$ had at least three involved LNs; 32 patients underwent fluorescence in situ hybridization (FISH) analysis for the detection of genomic aberrations and for 32 patients sequencing was done to analyze the IGHV gene status. One patient $(3.1 \%)$ had a $17 \mathrm{p}$ deletion, four $(12.5 \%)$ had a $11 \mathrm{q}$ deletion while $24(75.0 \%)$ patients had an unmutated IGHV gene status.

\section{Type of treatment and response}

Greek cohort. Twenty-seven patients $(27 / 50,54 \%)$ were in need of treatment either upon or very close to diagnosis. Median time to treatment from diagnosis (calculated including also patients that did not receive treatment) was 1.6 months. Most patients received a mild form of immunochemotherapy ranging from 14 (52\%) - receiving rituximab plus chlorambucil (R-CLB) to three (11\%) rituximab plus cyclophosphamide, vincristine and prednisolone (R-CVP), while two (7.4\%) and one (3.7\%) patients received fludarabine-cyclophosphamide-rituximab (FCR) and bendamustine-rituximab (BR) combinations respectively. Three $(11.1 \%)$ and two $(7.4 \%)$ patients were treated with rituximab and chlorambucil monotherapy respectively while one received radiotherapy (RT) and one corticosteroids alone (Table III).

Twenty-three cases could be assessed for response and among them $22(22 / 23,95.6 \%)$ responded. Four $(4 / 23$, $17.4 \%)$ entered complete remission (CR), 18 (18/23, 78.3\%) partial remission (PR) and one $(1 / 23,4.3 \%)$ had stable disease
(SD). Response according to type of first line treatment was as follows (Table IV): $85 \%$ (12/14) evaluable pts in the RCLB treatment group responded ( $3 \mathrm{CR}, 8 \mathrm{PR}$ ) and one had SD. All $(3 / 3,100 \%)$ patients who received R-CVP achieved PR while in the FCR treatment group one patient experienced $\mathrm{CR}$ and the other PR. All other assessable patients exposed to other treatment groups achieved PR.

GCLLSG clinical trial cohort. Median time from diagnosis to initiation of first treatment was 11.4 months. Thirty-nine $(39 / 45,87 \%)$ patients were treated with fludarabine-based regimens as first-line treatment - $19(19 / 31,42.2 \%)$ fludarabine-cyclophosphamide combination (FC) and 19 $(19 / 31,42.2 \%)$ FCR while only three $(3 / 31,6.7 \%)$ received the BR combination. One $(1 / 45,2.2 \%)$ patient received monotherapy with fludarabine $(\mathrm{F})$ and three $(3 / 45,6.7 \%)$ received monotherapy with chlorambucil (Table III). Data for response assessment was available in 39 cases. Thirty-six $(36 / 39,92 \%)$ responded, $13(13 / 39,33.3 \%)$ achieved CR and $23(23 / 39,59.0 \%)$ PR, while three $(3 / 39,7.7 \%)$ had no response (SD) or progressed PD. Disease response according to the type of first line treatment was as follows (Table IV): five of 19 patients in the FC group entered CR (26.3\%) while 14 had PR (73.7\%). In the FCR group, seven out of 16 patients achieved CR (43.8\%), seven (43.8\%) PR and two (12.5\%) did not respond with stable disease or PD; in the BR group two out of three (66\%) patients achieved PR; one patient who received $\mathrm{F}$ as a single agent reached $\mathrm{CR}$ and one patient placed on chlorambucil monotherapy showed no response. 
Table II. Patient characteristics at first-line treatment.

\begin{tabular}{|c|c|c|}
\hline Patient characteristics & $\begin{array}{l}\text { Greek } \\
\text { total } \\
\mathrm{N}(\%)\end{array}$ & $\begin{array}{l}\text { German } \\
\text { total } \\
\mathrm{N}(\%)\end{array}$ \\
\hline $\begin{array}{l}\text { All patients, } \mathrm{N} \\
\text { Age (vears) }\end{array}$ & 27 & 45 \\
\hline $\begin{array}{l}\text { Age (years) } \\
\text { Median (range) }\end{array}$ & $70(36-87)$ & $62(40-80)$ \\
\hline \multicolumn{3}{|l|}{ Age group (years) } \\
\hline$\leq 60$ & $4(14.8)$ & $19(42.2)$ \\
\hline$>60 \& \leq 65$ & $5(18.5)$ & $12(26.7)$ \\
\hline$>65 \& \leq 70$ & $4(14.8)$ & $7(15.6)$ \\
\hline$>70 \& \leq 75$ & $4(14.8)$ & $6(13.3)$ \\
\hline$>75$ & $10(37.0)$ & $1(2.2)$ \\
\hline Age group (years) & 27 & 45 \\
\hline$\leq 65$ & $9(33.3)$ & $31(68.9)$ \\
\hline$>65$ & $18(66.6)$ & $14(31.1)$ \\
\hline Ann Arbor stage, N(\%) & 27 & Not determined \\
\hline I & $2(7.4)$ & \\
\hline II & $0(0)$ & \\
\hline III & $1(3.7)$ & \\
\hline IV & $24(88.8)$ & \\
\hline B-symptoms & 27 & 45 \\
\hline No & $23(85.1)$ & $27(60.0)$ \\
\hline Yes & $4(14.8)$ & $18(40.0)$ \\
\hline ECOG performance status, $\mathrm{N}(\%)$ & 27 & 44 \\
\hline 0 & $12(44.4)$ & $26(59.1)$ \\
\hline 1 & $7(25.9)$ & $16(36.4)$ \\
\hline$>1$ & $8(29.6)$ & $2(4.5)$ \\
\hline LDH (U/l) & 25 & 44 \\
\hline$\leq 250$ & $12(48.0)$ & $32(72.7)$ \\
\hline$>250$ & $13(52.0)$ & $12(27.3)$ \\
\hline Deletion in $17 \mathrm{p}, \mathrm{N}(\%)$ & 11 & 33 \\
\hline Yes & $1(9.0)$ & $1(3.0)$ \\
\hline Deletion in $11 \mathrm{q}, \mathrm{N}(\%)$ & 8 & 33 \\
\hline Yes & $1(12.5)$ & $4(12.1)$ \\
\hline IGHV mutational status, $\mathrm{N}(\%)$ & 8 & 32 \\
\hline Unmutated & $5(62.5)$ & $24(75.0)$ \\
\hline Serum $\beta_{2}$-microglobulin $(\mathrm{mg} / \mathrm{l}), \mathrm{N}(\%)$ & 13 & 37 \\
\hline$\leq 3.5$ & $6(46.1)$ & $28(75.7)$ \\
\hline$>3.5$ & $7(53.8)$ & $9(24.3)$ \\
\hline Bone marrow biopsy $(\mathrm{N})$, & 25 & 9 \\
\hline Percentage of infiltration median $\%$ & $45 \%$ & $60 \%$ \\
\hline $\begin{array}{l}\text { Liver enlargement present, N (\%) } \\
\text { (hepatomegaly by any assessment) }\end{array}$ & 27 & 45 \\
\hline Yes & $5(18.5)$ & $18(40.0)$ \\
\hline $\begin{array}{l}\text { Spleen enlargement present, } \mathrm{N}(\%) \\
\text { (splenomegaly by any assessment) }\end{array}$ & 27 & 45 \\
\hline Yes & $7(26.9)$ & $26(57.8)$ \\
\hline $\begin{array}{l}\text { Bulky lymphadenopathy present, N (\%) } \\
\text { (any lymph node } \geq 10 \mathrm{~cm} \\
\text { by any assessment) }\end{array}$ & 27 & 45 \\
\hline Yes & $7(26.9)$ & $10(22.2)$ \\
\hline CT findings present, $\mathrm{N}(\%)$ & & \\
\hline $\begin{array}{l}\text { (any lymph node }>1.5 \mathrm{~cm} \\
\text { detected by CT scan) }\end{array}$ & 22 & 45 \\
\hline Yes & $21(95.4)$ & $25(55.6)$ \\
\hline $\begin{array}{l}\text { Number of involved lymph nodes, } \mathrm{N}(\%) \\
\text { (any lymph node }>1 \mathrm{~cm} \text { detected } \\
\text { by any assessment) }\end{array}$ & 27 & 45 \\
\hline 0 & $1(3.7)$ & $2(4.4)$ \\
\hline $1-2$ & $16(59.2)$ & $13(28.9)$ \\
\hline$\geq 3$ & $10(37.0)$ & $30(66.7)$ \\
\hline
\end{tabular}

ECOG: Eastern cooperative oncology group; LDH: lactate dehydrogenase; IGHV: immunoglobulin heavy chain variable; CT: computed tomography.
Table III. Type of first line treatment-Greek and German cohorts.

\begin{tabular}{lcc}
\hline Type of first-line treatment & $\begin{array}{c}\text { Greek } \\
\text { total } \\
\mathrm{N}(\%)\end{array}$ & $\begin{array}{c}\text { German } \\
\text { total } \\
\mathrm{N}(\%)\end{array}$ \\
\hline Patients with first-line treatment, N & 27 & 45 \\
R-CLB & $14(51.9)$ & \\
R-CVP & $3(11.1)$ & \\
R-B & $1(3.7)$ & $3(6.7)$ \\
FCR & $2(7.4)$ & $19(42.2)$ \\
CLB & $2(7.4)$ & $3(6.7)$ \\
R & $3(11.1)$ & \\
Other (RT, corticosteroids) & $2(7.4)$ & $1(2.2)$ \\
F & & $19(42.2)$ \\
FC & & \\
\hline
\end{tabular}

R-CLB: Rituximab-chlorambucil; R-CVP: rituximab, cyclophosphamide, vincristine, prednisolone; R-B: rituximab-bendamustine; RT: radiotherapy; F: fludarabine; FC: fludarabine, cyclophosphamide; FCR: fludarabine, cyclophosphamide, rituximab; R: rituximab.

\section{Discussion}

The International Workshop on CLL definition of SLL requires the presence of enlarged lymph nodes with the same tissue morphology and immunophenotype as CLL, with no cytopenias due to bone marrow infiltration and fewer than $5 \times 10^{9} / \mathrm{L}$ peripheral blood B cells (18).

Because of its rarity only small series of SLL have been reported and SLL patients are usually incorporated in larger CLL series reported within clinical trials (7). As a result, no specific systematic analysis of this subgroup has been performed.

Although the WHO classification system does not recognize SLL and CLL as separate entities, these patients are often treated differently both in clinical trials and in everyday clinical practice, raising the obvious question about the optimal therapeutic approach for this group of patients.

The present study is indeed one of the largest series exclusively including SLL patients diagnosed according to more modern criteria, deriving from both clinical trials and "real-life" clinical practice, and focusing on the aforementioned question (19). This investigation reveals that SLL patients enrolled in clinical trials in the era before targeted therapies were treated mostly with fludarabine-based regimens, including the FCR combination, followed by the BR combination and CLB, adopting the same therapeutic algorithms as in CLL. This therapeutic approach is effective and achieves high response rates (92\%) including CRs (33\%) exclusively in the fludarabine-based treatment arms.

On the other hand, outside of clinical trials, as in the Greek cohort reported here, SLL patients were treated more heterogeneously and mostly received lymphoma- type treatment protocols. Here, SLL patients were treated mostly with mild 
Table IV. Response according to first-line treatment in both cohorts.

\begin{tabular}{|c|c|c|c|c|c|c|c|c|c|}
\hline First line treatment & $\begin{array}{l}\text { R-CLB } \\
\text { Greek } \\
\mathrm{N}(\%)\end{array}$ & $\begin{array}{l}\text { R-CVP } \\
\text { Greek } \\
\mathrm{N}(\%)\end{array}$ & $\begin{array}{c}\text { FCR } \\
\text { Greek/German } \\
\mathrm{N}(\%)\end{array}$ & $\begin{array}{c}\text { BR } \\
\text { Greek/German } \\
\mathrm{N}(\%)\end{array}$ & $\begin{array}{c}\text { CLB } \\
\text { Greek/German } \\
\mathrm{N}(\%)\end{array}$ & $\begin{array}{c}\mathrm{F} \\
\text { German } \\
\mathrm{N}(\%)\end{array}$ & $\begin{array}{c}\mathrm{FC} \\
\text { German } \\
\mathrm{N}(\%)\end{array}$ & $\begin{array}{c}\mathrm{R} \\
\text { Greek } \\
\mathrm{N}(\%)\end{array}$ & $\begin{array}{l}\text { Other } \\
\text { Greek } \\
\mathrm{N}(\%)\end{array}$ \\
\hline $\begin{array}{l}\text { Patients with first-line } \\
\text { treatment, } \mathrm{N}\end{array}$ & 14 & 3 & $2 / 19$ & $1 / 3$ & $2 / 3$ & 1 & 19 & 3 & 2 \\
\hline Missing response & $2(14.28)$ & $0(0.0)$ & $0(0.0) / 3(15.8)$ & $0(0.0) / 1(33.3)$ & $0(0.0) / 2(66.7)$ & $0(0.0)$ & $0(0.0)$ & $0(0.0)$ & $2(100)$ \\
\hline $\begin{array}{l}\text { Response to first-line } \\
\text { treatment }\end{array}$ & 12 & 3 & $2 / 16$ & $1 / 2$ & $2 / 1$ & 1 & 19 & 3 & 0 \\
\hline $\mathrm{CR}$ & $3(25.0)$ & $0(0.0)$ & $1(50.0) / 7(43.8)$ & $0(0.0) / 0(0.0)$ & $0(0.0) / 0(0.0)$ & $1(100.0)$ & $5(26.3)$ & $0(0.0)$ & - \\
\hline PR & $8(66.6)$ & $3(100.0)$ & $1(50.0) / 7(43.8)$ & $1(100.0) / 2(100.0)$ & $2(100.0 /) 0(0.0)$ & $0(0.0)$ & $14(73.7)$ & $3(100.0)$ & - \\
\hline $\mathrm{SD} / \mathrm{PD}$ & $1(8.3)$ & $0(0.0)$ & $0(0.0) / 2(12.5)$ & $0(0.0) / 0(0.0)$ & $(0.0) / 1(100.0)$ & $0(0.0)$ & $0(0.0)$ & $0(0.0)$ & - \\
\hline
\end{tabular}

R-CLB: Rituximab-chlorambucil; R-CVP: rituximab, cyclophosphamide, vincristine, prednisolone; FCR: fludarabine, cyclophosphamide, rituximab; BR: bendamustine, rituximab; CLB: chlorambucil; F: fludarabine; FC: fludarabine, cyclophosphamide; R: rituximab; CR: complete response; PR: partial response; SD/PD: stable disease/progression of disease.

immunochemotherapy (mainly the R-CLB combination and less frequently R-CVP). Only two patients received the FCR combination and interestingly there were even individual cases who received monotherapy with rituximab or radiotherapy alone. Overall response rates were high (95\%) reaching CR (18\%, 3 patients in the R-CLB group and 1 in FCR group).

The Ann-Arbor staging system for SLL patients is still used in everyday clinical practice and is quite widespread. Of note is the fact that the use of this staging system can identify patients with SLL in whom lymphoma is localized to a single group of lymph nodes or lymph nodes present on one side of the diaphragm who could benefit from the use of local radiotherapy. Previously, published data have shown that if the bone marrow is not involved, this subset of SLL patients is potentially curable after involved or extended field radiotherapy, achieving $80 \%$ freedom from relapse in stage I and $62 \%$ in stage II (20).

Survival analysis showed that patients with SLL in both cohorts had an excellent prognosis with a 5-year OS of $86.2 \%$ and $90.1 \%$ for the German and Greek cohorts, respectively. The presence of $17 \mathrm{p}$ deletion had statistical significance for PFS in the univariate analysis of the GCLLSG cohort. In the univariate analysis of SLL patients in the Greek cohort, the presence of B-symptoms, ECOG performance status greater than " 0 " and the age older than 65 years had a significant poor prognostic impact on OS. Other clinical and biological parameters had no statistically significant impact on outcome.

Time from diagnosis to treatment initiation was significantly shorter for SLL patients in the Greek "real-life" cohort (1.6 months) than for those treated in the framework of the GCLLSG trials (11.4 months). We feel that this reflects the fact that in everyday practice clinicians more commonly use the lymphoma criteria for initiation of treatment and begin therapy for SLL much sooner compared to those participating physicians enlisting patients in the GCLLSG clinical trials.
We also attempted to evaluate the prognostic role of two specific parameters - the presence of PCs in lymphoma tissue biopsies and the size of lymph nodes, which according to the updated WHO classification, could be utilized to identify a subset of SLL patients with better prognosis (5). However, our results showed that the size of lymph nodes had no prognostic significance in both SLL cohorts. Moreover, in the Greek "real life" cohort, lymph node sections were available in the majority of patients and PCs were seen in most of the cases $(65 \%)$. These data are in line with the data reported in our previous studies as well as reported by other investigators (14, 21-22). Although, according to Kaplan Meier curves a trend for better survival for SLL patients without detectable PCs could be assumed since all events occurred in the group of patients with detectable PCs, in our analysis this correlation failed to attain statistical significance. Similarly, in 2011 Gibson et al. reported that biopsies containing CLL/SLL-type cells, but lacking PCs in patients with no enlarged or only slightly enlarged lymph nodes on imaging, are indicative of very indolent disease and could perhaps be considered as a tissue equivalent of monoclonal B-cell lymphocytosis rather than overt small lymphocytic lymphoma (6).

In conclusion, this study shows that SLL patients in "real life" are usually treated as low-grade lymphomas with the administration of less toxic therapeutic agents resulting in high response rates which are similar to those obtained in clinical trials. In addition, our study provides further data supporting the adverse prognostic significance of the presence of PCs in lymph nodes.

\section{Conflicts of Interest}

The Authors report no conflicts of interest regarding this study. 


\section{Authors' Contributions}

Conception/Design: Sotirios Sachanas, Gerassimos Pangalis, Anna Maria Fink, Kirsten Fisher, Jasmin Bahlo, Barbara Eichhorst, Michael Hallek. Provision of study material or patients: Sotirios Sachanas, Anna Maria Fink, Kirsten Fisher, Barbara Eichhorst, Michael Hallek, Xanthi Yiakoumis, Maria Moschogiannis, Efstathios Koulieris, Vassiliki Bartzi, Christina Kalpadakis, Theodoros Vassilakopoulos Maria Angelopoulou, Marie-Christine Kyrtsonis. Data analysis and interpretation: Georgia Levidou, Jasmin Bahlo. Manuscript writing: Sotirios Sachanas, Gerassimos Pangalis, Anna-Maria Fink, Barbara Eichhorst. Final approval of manuscript: Sotirios Sachanas, Anna Maria Fink, Barbara Eichhorst, Gerassimos Pangalis, Michael Hallek.

\section{References}

1 The Non-Hodgkin's Lymphoma Classification Project: A clinical evaluation of the International Lymphoma Study Group classification of non-Hodgkin's lymphoma: The Non-Hodgkin's Lymphoma Classification Project. Blood 89: 3909-3918, 1997. PMID: 9166827.

2 Pangalis GA, Angelopoulou MK, Vassilakopoulos TP, Siakantaris MP and Kittas C:B-chronic lymphocytic leukemia, small lymphocytic lymphoma, and lymphoplasmacytic lymphoma, including Waldenström's macroglobulinemia: A clinical, morphologic, and biologic spectrum of similar disorders. Semin Hematol 36:104-114,1999. PMID: 10319379.

3 Hallek M, Shanafelt TD and Eichhorst B: Chronic Lymphocytic Leukemia. Lancet 391: 1524-1537, 2018. PMID: 29477250. DOI: $10.1016 / \mathrm{S} 0140-6736(18) 30422-7$

4 Campo E, Swerdlow SH, Harris NL, Pileri S, Stein H and Jaffe ES: The 2008 WHO classification of lymphoid neoplasms and beyond: evolving concepts and practical applications. Blood 19: 5019-5032, 2011. PMID: 21300984. DOI: 10.1182/blood-2011-01-293050

5 Swerdlow SH, Campo E, Pileri SA, Harris NL, Stein H, Siebert R, Advani R, Ghielmini M, Salles GA, Zelenetz AD and Jaffe ES: The 2016 revision of the World Health Organization classification of lymphoid neoplasms. Blood 127: 2375-2390, 2016. PMID: 26980727. DOI: 10.1182/blood-2016-01-643569

6 Gibson SE, Swerdlow SH, Ferry JA, Surti U, Cin PD, Harris NL and Hasserjian RP: Reassessment of small lymphocytic lymphoma in the era of monoclonal B-cell lymphocytosis. Haematologica 96: 1144-1152, 2011. PMID: 21546505. DOI: 10.3324/haematol.2011.042333

7 Ben-Ezra J, Burek JS, Swartz WC, Brownell MD, Brynes RK, Hill LR, Nathwani BN, Oken MM, Wolf BC, Woodruff R and Rappaport H: Small Lymphocytic Lymphoma: A clinicopathologic analysis of 265 cases. Blood 73: 579-587, 1989. PMID: 2644979.

8 Nola M, Pavletic SZ, Weisenburger DD, Smith LM, Bast MA, Vose JM and Armitage JO: Prognostic factors influencing survival in patients with B-cell small lymphocytic lymphoma Am J Hematol 77: 31-35, 2004. PMID: 15307103. DOI: 10.1002/ajh.20137

9 Bergmann A, Busch R, Eichhorst B, Buehler A, Fischer N, Eckart MJ, Kaiser UV, Jäger U, Hopfinger G, Wendtner C, Fischer K, Emmerich B, Döhner H, Hallek M and Stilgenbauer $\mathrm{S}$ : Overall survival in early stage chronic lymphocytic leukemia patients with treatment indication due to disease progression: Follow-up data of the CLL1 trial of the German CLL Study Group (GCLLSG). Blood 122: 4127, 2013. PMID: 28804126.
10 Eichhorst BF, Busch R, Hopfinger G, Pasold R, Hensel M, Steinbrecher C, Siehl S, Jäger U, Bergmann M, Stilgenbauer S, Schweighofer C, Wendtner CM, Döhner H, Brittinger G, Emmerich B and Hallek M: Fludarabine plus cyclophosphamide versus fludarabine alone in first-line therapy of younger patients with chronic lymphocytic leukemia. Blood 107: 885-891, 2006. PMID: 16219797. DOI: 10.1182/blood-2005-06-2395

11 Eichhorst BF, Busch R, Stilgenbauer S, Stauch M, Bergmann MA, Ritgen M, Kranzhöfer N, Rohrberg R, Söling U, Burkhard O, Westermann A, Goede V, Schweighofer CD, Fischer K, Fink AM, Wendtner CM, Brittinger G, Döhner H, Emmerich B, Hallek M and German CLL Study Group (GCLLSG): First line therapy with fludarabine compared with chlorambucil does not result in a major benefit for elderly patients with advanced chronic lymphocytic leukemia. Blood 15: 3382-3391, 2009. PMID: 19605849. DOI: 10.1182/blood-2009-02-206185

12 Hallek M, Fischer K, Fingerle-Rowson G, Fink AM, Busch R, Mayer J, Hensel M, Hopfinger G, Hess G, von Grünhagen U, Bergmann M, Catalano J, Zinzani PL, Caligaris-Cappio F, Seymour JF, Berrebi A, Jäger U, Cazin B, Trneny M, Westermann A, Wendtner CM, Eichhorst BF, Staib P, Bühler A, Winkler D, Zenz T, Böttcher S, Ritgen M, Mendila M, Kneba M, Döhner H, Stilgenbauer S, International Group of Investigators and German Chronic Lymphocytic Leukaemia Study Group: Addition of rituximab to fludarabine and cyclophosphamide in patients with chronic lymphocytic leukaemia: A randomised, open-label, phase 3 trial. Lancet 376: 1164-1174, 2010. PMID: 20888994. DOI: 10.1016/S0140-6736(10)61381-5

13 Fischer K, Cramer P, Busch R, Böttcher S, Bahlo J, Schubert J, Pflüger KH, Schott $S$, Goede V, Isfort $S$, von Tresckow J, Fink AM, Bühler A, Winkler D, Kreuzer KA, Staib P, Ritgen M, Kneba M, Döhner H, Eichhorst BF, Hallek M, Stilgenbauer S and Wendtner CM: Bendamustine in combination with rituximab for previously untreated patients with chronic lymphocytic leukemia: a multicenter phase II trial of the German Chronic Lymphocytic Leukemia Study Group. J Clin Oncol 30: 32093216, 2012. PMID: 22869884. DOI: 10.1200/JCO.2011.39.2688

14 Schmid C and Isaacson PG: Proliferation centers in B-cell malignant lymphoma, lymphocytic (B-CLL): An immunophenotypic study. Histopathology 24: 445-451, 1994. PMID: 8088716.

15 Soma LA, Craig FE and Swerdlow SH: The proliferation center microenvironment and prognostic markers in chronic lymphocytic leukemia/small lymphocytic lymphoma. Hum Pathol 37: 152-159, 2006. PMID: 16426914. DOI: 10.1016/ j.humpath.2005.09.029

16 Bonato M, Pittaluga S, Tierens A, Bonato M, Criel A, Verhoef G, Wlodarska I, Vanutysel L, Michaux L, Vandekerckhove P, Van den Berghe $\mathrm{H}$ and De Wolf-Peeters C: Lymph node histology in typical and atypical chronic lymphocytic leukemia. Am J Surg Pathol 22: 49-56, 1998. PMID: 9422315.

17 Ponzoni M, Doglioni C and Caligaris-Cappio F: Chronic lymphocytic leukemia: the pathologist's view of lymph node microenvironment. Semin Diagn Pathol 28: 161-166, 2011. PMID: 21842701. DOI: 10.1053/j.semdp.2011.02.014

18 Hallek M, Cheson BD, Catovsky D, Caligaris-Cappio F, Dighiero G, Döhner H, Hillmen P, Keating MJ, Montserrat E, Rai KR, Kipps TJ and International Workshop on Chronic Lymphocytic Leukemia: Guidelines for the diagnosis and treatment of chronic lymphocytic leukemia: A report from the 
International Workshop on Chronic Lymphocytic Leukemia (IWCLL) updating the National Cancer Institute-Working Group (NCI-WG) 1996 guidelines. Blood 111: 5446-5456, 2008. PMID: 18216293. DOI: 10.1182/blood-2007-06-093906

19 Martínez-Trillos A, Pinyol M, Delgado J, Aymerich M, Rozman M, Baumann T, González-Díaz M, Hernández JM, Alcoceba M, Muntañola A, Terol MJ, Avarro NB, Giné E, Jares $\mathrm{P}$, Beà $\mathrm{S}$, Navarro A, Colomer D, Nadeu F, Colado E, Payer AR, GarcíaCerecedo T, Puente XS, López-Otin C, Campo E, LópezGuillermo A and Villamor N: The mutational landscape of small lymphocytic lymphoma compared to non-early stage chronic lymphocytic leukemia. Leuk Lymphoma 10: 2318-2326, 2018. PMID: 29115891. DOI: 10.1080/10428194.2017.1397660

20 Morrison WH, Hoppe RT, Weiss LM, Picozzi Jr VJ and Horning SJ: Small lymphocytic lymphoma. J Clin Oncol 5: 598-606, 1989. PMID: 2651577. DOI: 10.1200/JCO.1989.7.5.598

21 Sachanas S, Levidou G, Angelopoulou MK, Moschogiannis M, Yiakoumis X, Kalpadakis C, Vassilakopoulos TP, Kontopidou F, Tsirkinidis P, Dimitrakopoulou A, Kokoris S, Dimitriadou E, Kyrtsonis MC, Panayiotidis P, Papadaki H, Patsouris E, Korkolopoulou P and Pangalis GA: Apoptotic and proliferative characteristics of proliferation centers in lymph node sections of patients with chronic lymphocytic leukemia. Leuk Lymphoma 55: 571-582, 2014. PMID: 23697878. DOI: 10.3109/10428194. 2013.806802

22 Giné E, Martinez A, Villamor N, López-Guillermo A, Camos M, Martinez D, Esteve J, Calvo X, Muntañola A, Abrisqueta P, Rozman M, Rozman C, Bosch F, Campo E and Montserrat E: Expanded and highly active proliferation centers identify a histological subtype of chronic lymphocytic leukemia ("accelerated" chronic lymphocytic leukemia) with aggressive clinical behavior. Haematologica 95: 1526-1533, 2010. PMID: 20421272. DOI: 10.3324/haematol.2010.022277

Received March 25, 2019 Revised April 16, 2019 Accepted April 19, 2019 